\title{
CAPACITAÇÃO EM EAD PARA TUTORES NO CURSO DE ESPECIALIZAÇÃO EM FORMAÇÃO PEDAGÓGICA PARA DOCENTES NO IFCE: UMA ANÁLISE DA PRÁXIS PEDAGÓGICA
}

\author{
Ailton Batista de Albuquerque Junior ${ }^{1}$, Marta Alves Silva ${ }^{2}$ \\ Instituto Federal de Educação, Ciência e Tecnologia do Ceará - IFCE ${ }^{1}$ campus Itapipoca ${ }^{2}$ campus Fortaleza \\ <ailton.junior@ifce.edu.br>.<smart.alves@gmail.com> \\ DOI: $10.21439 /$ conexoes.v11i2.1038
}

\begin{abstract}
Resumo. O artigo tem a modesta pretensão de organizar panoramicamente a trajetória da modalidade EAD no mundo, no Brasil e no Instituto Federal de Educação, Ciência e Tecnologia do Ceará (IFCE), com o propósito de evidenciar os ranços e avanços acerca dos conteúdos, metodologia, didática e avaliação da aprendizagem dos alunos, ou seja, investigar se a prática está de acordo com as teorias pedagógicas para caracterizar a práxis. Objetiva ainda divulgar os resultados para os participantes da pesquisa, como forma de incentivá-los a refletir sobre suas insatifações, demandas e fatores positivos; propor mudanças importantes para que haja maior êxito na relação ensino-aprendizagem; servir de referência para a Direção de Ensino a Distância do IFCE para que nas próximas turmas possam ratificar os pontos positivos e corrigir os erros, de modo que a formação teórico-metodológica, ético-política e técnico-operacional sejam condizentes com a práxis pedagógica, e mais, que tecnologias contemporâneas de informação e de comunicabilidade no contexto educacional, principalmente Educação a Distância, sejam transformadoras, pois elas potencializam e pressupõem um outro paradigma educacional, que passa pela descentralização do currículo e do empoderamento dos alunos. A priori, utilizou-se de pesquisa bibliográfica para fundamentação e uso de questionário e a posteriori de pesquisa de campo, tendo em vista o estudo ocorrer in lócus, percebeu-se que a maioria dos participantes do estudo elucidaram algumas lacunas no curso como conteúdos insuficientes entre outras peculiaridades.
\end{abstract}

Palavras-chaves: EaD. Avaliação. Didática. Metodologia. Tecnologias.

Abstract. The paper has the modest pretension to organize the path of the EAD modality in the world, in Brazil and in the Federal Institute of Education, Science and Technology of Ceará (IFCE), with the purpose of evidencing the ranks and advances about the contents, methodology, Didactics and assessment of student learning. It also aims to disseminate the results to the participants of the research, as a way to encourage them to reflect on their insatiations, demands and positive factors; Propose important changes to make the teaching-learning relationship more successful; To serve as a reference for the Distance Learning Department of the IFCE so that in the next classes they can ratify the positive points and correct the mistakes, so that the theoretical-methodological, ethical-political and technical-operational training is in line with the pedagogical praxis, And more, that contemporary technologies of information and communicability in the educational context, especially Distance Education, are transformative, since they potentiate and presuppose another educational paradigm that goes through the decentralization of the curriculum and the empowerment of the students. A priori, a bibliographical research was used for the foundation and use of questionnaires and a posteriori of field research, in view of the study occurring in loco, it was noticed that the majority of the participants of the study elucidated some shortcomings in the course as insufficient contents Among other peculiarities.

Keywords: Distance education. Evaluation. Teaching. Methodology. Technologies.

\section{INTRODUÇÃO}

Ao concluir o curso de capacitação EAD para atuar na Especialização em Formação Pedagógica para docen- 
tes do IFCE, com início em janeiro de ano de 2016, na Modalidade a Distância realizou-se uma pesquisa para avaliar os aspectos positivos e negativos dos conteúdos, da didática, metodologia, avaliação, plataforma, acesso, comunicação e outros itens referentes a esse curso de formação.

Muitas pessoas se perguntam sobre o que vem a ser EAD. De acordo com o Decreto 5.622/2005, no Brasil a Educação a Distância é definida como sendo uma:

Modalidade educacional na qual a mediação didático-pedagógica nos processos de ensino e aprendizagem ocorre com a utilização de meios e tecnologias de informação e comunicação, com estudantes e professores desenvolvendo atividades educativas em lugares ou tempos diversos.

Morán (2016) elucida que essa modalidade de educação é efetivada através do intenso uso de tecnologias de informação e comunicação, podendo ou não apresentar momentos presenciais.

Vale frisar, enfaticamente, que Educação a distância é uma forma nas qual a Educação pode ocorrer não necessariamente em detrimento da educação presencial, uma vez que ambas podem se dar simultaneamente de maneira eficaz e eficiente. Atualmente, a educação a distância vem ganhando importantes dimensão, em razão da crescente demanda por cursos formais e informais através dessa modalidade de ensino.

Apesar do crescimento e aceitação por grande parte da população, um fator que merece ser abordado, sobretudo, é a questão do preconceito dos leigos que afirmam que os cursos ministrados nessa modalidade não têm regulamentação adequada, controle do aprendizado, etc. No entanto, pode-se perceber que não passa de mero aforismo, tendo em vista que esse ramo da Educação conta com diversos dispositivos que legalizam e regulamentam os procedimentos relativos a mesma, quais sejam: artigo 80 da Lei de Diretrizes e Bases da Educação Nacional no qual há o incentivo pelo poder público de qualquer instituição de ensino ministrar a Educação na modalidade EAD, desde que esteja credenciada na União, uma vez que tal procedimento é necessário, tendo em vista a elaboração de exames e emissão de diplomas; o Decreto $\mathrm{n}^{\circ} 5.622$ /2005 que regulamenta o art. 80 da Lei no 9.394/96, conceituando o que vem a ser essa modalidade de educação, elencando ainda as especificidades na metodologia, gestão e avaliação da modalidade; o Decreto ${ }^{0} 5.773$ /2006 que fala sobre o exercício das funções de regulação, supervisão e avaliação de instituições de educação superior e cursos superiores de graduação e sequenciais no sistema federal de ensino com parte referente à EAD; o Decreto $n^{\circ}$ 2.494/98 que regulamenta o Art. 80 da Lei 9.394/96, especificando as normas quanto à elaboração, certificação, regulamentação, oferta, credenciamento das Instituições, autorização, reconhecimento de cursos, avaliação, padrões de qualidade, matrículas, transferências, aproveitamento de créditos, que deverão, no prazo de um ano da vigência deste Decreto, atender às exigências nele estabelecidas. Cita ainda que os cursos de educação a distância podem ser organizados em regime especial, com flexibilidade de horários, duração e requisitos para admissão, porém sem prejuízo dos objetivos e das diretrizes curriculares fixadas em nível nacional. Todos esses dispositivos legais põem por terra as argumentações daqueles que se colocam contrários à EAD.

Hodiernamente, a Educação a Distância tornou-se um instrumento primordial para a promoção de oportunidades, visto que muitos indivíduos, apropriandose deste tipo de ensino, podem concluir cursos informais, técnicos, treinamentos governamentais, a educação básica, e até cursos de nível superior com qualidade e abraçar novas oportunidades profissionais, corroborando assim o pensamento de Maia e Mattar (2007) sobre $\mathrm{o}$ assunto.

\section{EDUCAÇÃO A DISTÂNCIA NO MUNDO: BREVE RETROSPECTIVA}

Segundo Gouvêa e Oliveira (2006), a origem da Educação a Distância possui extrema ligação com as cartas de São Paulo, destinadas aos cristãos da Ásia menor, contidas na Bíblia Sagrada. Tais epístolas ensinavam as pessoas a se comportarem de acordo com os dogmas cristãos em ambientes desfavoráveis e teriam sido escritas em meados do século I. Avançando no tempo, é possível listar alguns episódios históricos que consolidaram a Educação a Distância no mundo, a partir do século XVIII (VASCONCELOS, 2010, GOUVÊA; OLIVEIRA, 2006), mais precisamente em 1728, data que se poderia considerar como início da Educação a Distância. Nesse ano, a Gazeta de Boston, edição de 20 de março, anuncia um curso onde o professor Philips oferecia uma diversidade de apostilas para ensino e tutoria através de cartas.

Após um leque de iniciativas de pioneiros, tomadas por um longo período e por vários profissionais do ensino, apenas no século XIX a Educação a Distância começa a existir institucionalmente. Vejamos:

- 1829 - na Suécia é inaugurado o Instituto Líber Hermondes, possibilitando a quase 151.000 pessoas estudarem cursos através da modalidade de Educação a Distância;

- 1829 - na Suécia é inaugurado o Instituto Líber Hermondes, possibilitando a quase 151.000 pes- 
soas estudarem cursos através da modalidade de Educação a Distância;

- 1922 - na União Soviética iniciam-se cursos por correspondência;

- 1947 - inicia-se a transmissão das aulas de quase todas as matérias literárias da Faculdade de Letras e Ciências Humanas de Paris, França, por meio da Rádio Sorbonne;

- 1956 - a Chicago TV College, Estados Unidos, inicia a transmissão de programas educativos pela televisão, influenciando outras universidades do país que não tardaram em criar unidades de ensino a distância, baseadas fundamentalmente na televisão;

- 1969 - é criada no Reino Unido, a Fundação da Universidade Aberta;

- 1971 - a Universidade Aberta Britânica é fundada;

- 1972 - na Espanha é fundada a Universidade Nacional de Educação a Distância;

- 1977 - na Venezuela é criada a Fundação da Universidade Nacional Aberta;

- 1987 - é criada a Fundação da Associação Europeia de Universidades de Ensino a Distância; e em

- 1988 - é criada em Portugal a Fundação da Universidade Aberta.

\subsection{Educação a distância no Brasil: como tudo co- meçou}

Acredita-se que, o início das experiências em Educação a Distância no Brasil não tenha sido registrado, tendo em vista que os primeiros dados conhecidos são do século XX. Portanto, disponibiliza-se abaixo diversos episódios que marcaram a história da Educação a Distância no nosso país (MAIA; MATTAR, 2007; MARCONCIN, 2010; RODRIGUES, 2010, SANTOS, 2010):

- 1904 - é registrado pelo Jornal do Brasil a primeira edição d de classificados, anunciando curso profissionalizante de datilografia;

- 1923 - cria-se a Rádio Sociedade do Rio de Janeiro, através da liderança de Morize e RoquettePinto, que oferecia os seguintes cursos de Educação a distância: Conceitos e história no Brasil, Francês, Silvicultura, Literatura Francesa, Esperanto, Radiotelegrafia e Telefonia. Portanto, iniciava-se a Educação a Distância via rádio no território brasileiro;
- 1939 - em São Paulo, surge o Instituto Monitor, o primeiro instituto brasileiro a oferecer sistematicamente cursos profissionalizantes a distância por correspondência;

- 1947 - patrocinada pelo Serviço Nacional de Aprendizagem Comercial (SENAC), Serviço Social do Comércio (SESC) e emissoras associadas aparece a nova Universidade do Ar. O objetivo era oferecer cursos comerciais radiofônicos. A experiência durou até 1961, entretanto a experiência do SENAC com a Educação a Distância continua até hoje;

- 1970 - surge o Projeto Minerva, um convênio entre o Ministério da Educação, a Fundação Padre Landell de Moura e Fundação Padre Anchieta, cuja meta era a utilização do rádio para a educação e a inclusão social de adultos. O projeto foi mantido até o início da década de 1980;

- 1974 - surge o Instituto Padre Reus e na TV Ceará começam os cursos das antigas $5^{\mathrm{a}}$ à $8^{\mathrm{a}}$ séries (atuais $6^{\circ}$ ao $9^{\circ}$ ano do Ensino Fundamental), com material televisivo, impresso e monitores;

- 1976 - é criado o Sistema Nacional de Teleducação, com cursos através de material instrucional;

- 1979 - a Universidade de Brasília, pioneira no uso da Educação a Distância no ensino superior no Brasil, cria cursos veiculados por jornais e revistas. Em 1989 é instalado o Centro de Educação Aberta, Continuada, a Distância (CEAD) e lançado o Brasil EAD;

- 1983 - o SENAC desenvolveu uma série de programas radiofônicos sobre orientação profissional na área de comércio e serviços, denominada "Abrindo Caminhos";

- 1992 - é criada a Universidade Aberta de Brasília, acontecimento bastante importante na para a Educação a Distância do nosso país;

- 1996 - o Ministério da Educação cria a Secretaria de Educação a Distância (SEED), parte de uma política que privilegia a democratização e a qualidade da educação brasileira. É neste ano, também, que a Educação a Distância surge oficialmente no Brasil, sendo as bases legais para essa modalidade de educação estabelecidas pela Lei de Diretrizes e Bases da Educação Nacional n ${ }^{\circ} 9.394$, de 20 de dezembro de 1996, embora somente regulamentada em 20 de dezembro de 2005 pelo Decreto $\mathrm{n}^{\circ}$ 
5.622 (BRASIL, 2005) que revogou os Decretos $\mathrm{n}^{\circ} 2.494$ de 10/02/98;

- 2005 - é criada a Universidade Aberta do Brasil, uma parceria entre o MEC, estados e municípios, integrando cursos, pesquisas e programas de educação superior a distância.

- 2006 - entra em vigor o Decreto $n^{\circ}$ 5.773, de 09 de maio de 2006, que dispõe sobre o exercício das funções de regulação, supervisão e avaliação de instituições de educação superior e cursos superiores de graduação e sequenciais no sistema federal de ensino, incluindo os da modalidade a distância (BRASIL, 2006).

- 2007 - entra em vigor o Decreto n ${ }^{\circ}$ 6.303, de 12 de dezembro de 2007, que altera dispositivos do Decreto $\mathrm{n}^{\circ} 5.622$ que estabelece as Diretrizes e Bases da Educação Nacional (BRASIL, 2007).

- 2009 - entra em vigor a Portaria $n^{0} 10$, de 02 julho de 2009, que fixa critérios para a dispensa de avaliação in loco e dá outras providências para a Educação a Distância no Ensino Superior no Brasil (BRASIL, 2009)

- 2011 - a Secretaria de Educação a Distância é extinta. Torna-se importante citar que entre as décadas de 1970 e 1980, fundações privadas e organizações não governamentais iniciaram a oferta de cursos supletivos a distância, no modelo de Teleducação, com aulas via satélite, complementadas por kits de materiais impressos, demarcando a chegada da segunda geração de Educação a Distância no país.

\subsection{Educação a distância no IFCE: realidade e perspectivas}

No IFCE, a Educação a Distância já é uma realidade graças ao sistema Universidade Aberta do Brasil (UAB) e Escola Técnica Aberta do Brasil (E-tec), que abriram as portas para a expansão, consolidação e interiorização da oferta do ensino técnico e superior, gratuito e de qualidade no Brasil e, em especial, no Ceará.

Com base em dados do MEC, seguem algumas informações importantes:

a. UAB - Universidade Aberta do Brasil

O Ministério da Educação, no ano de 2005, criou o Sistema UAB, sendo inauguradas as turmas pioneiras em EAD no IFCE, apenas em 2007. Naquele tempo ofertou-se 400 vagas para dois cursos de graduação. Vale salientar que hoje, a Diretoria de EaD oferece mais 7 mil vagas, distribuídas em cursos nos diversos níveis.

b. Escola Técnica Aberta do Brasil (E-tec)

Esse programa se insere no âmbito da política de expansão da educação profissionalizante, como uma das ações do Plano de Desenvolvimento da Educação. Trata-se de um passo meritório para a democratização e redemocratização do acesso ao ensino técnico público, por meio da modalidade de Educação a Distância.

c. Pró-funcionário

Programa de Formação Inicial em Serviço dos Profissionais da Educação Básica dos Sistemas de Ensino Público ? Pro funcionário. O projeto objetiva, por meio do ensino a distância, oferecer formação técnica, em nível médio, aos funcionários das redes públicas de educação básica dos sistemas de ensino, nas habilitações de Infraestrutura Escolar, Secretariado Escolar, Multimeios Didáticos e Alimentação Escolar.

\section{PROCEDIMENTOS METODOLÓGICOS}

A pesquisa fez uso de uma abordagem qualitativa, tendo em vista que buscou conhecer a realidade da socialização dos conteúdos elencados no conteúdo programático, além de diagnosticar os pontos positivos e negativos em relação a conteúdos, didática, metodologias, avaliação, assiduidade na plataforma e flexibilidade por parte dos tutores, aspectos democráticos e propostas para implementação e inovação de novos temas e módulos na matriz curricular do itinerário formativo, de acordo com o que consta no questionário em apêndice. Indispensável citar que essas indagações buscam uma análise da descrição e as percepções subjetivas dos sujeitos envolvidos na investigação (BOGDAN et al. 1994).

Minayo (1994, p. 21-22) e Alves (1991, p. 09-13) ratificam as ideias dos retrocitados autores ao escrever que:

A pesquisa qualitativa responde a questões muito particulares. Ela se preocupa [...] com um nível de realidade que não pode ser quantificado. Ou seja, ela trabalha com o universo de significados, motivos, aspirações, crenças, valores e atitudes, o que corresponde a um espaço mais profundo das relações, dos processos e dos fenômenos que não podem ser reduzidos à operacionalização de variáveis.

Para a fundamentação do arcabouço teórico foi utilizada a pesquisa bibliográfica de autores renomados em Educação através de livros e artigos científicos, evitando citações demasiadas da internet, inclusive de sites 

NO IFCE: UMA ANÁLISE DA PRÁXIS PEDAGÓGICA

de procedência duvidosa, tendo em vista recomendações de (GIL, 2008).

A pesquisa de campo foi essencial uma vez que esta é indicada para a observação e reflexão de fatos e fenômenos e como eles se desenrolam no concreto. Ruiz (2002, p. 50) corrobora dizendo que "a pesquisa de campo consiste na observação dos fatos tal como ocorrem espontaneamente, na coleta de dados e no registro de variáveis presumivelmente relevantes para ulteriores análises". Foi realizada durante dois encontros presenciais através de questionário, contendo 10 (dez) perguntas, conforme em apêndice.

Os sujeitos da pesquisa foram 10 (dez) alunos, ou seja, $66 \%$ dos concludentes da capacitação, lembrando que a turma possuía um número de 15 (quinze) alunos, mas nem todos quiseram participar. Vale salientar que todo o material colhido foi incinerado, sendo tal procedimento justificável em virtude de conter nome de cada aluno e as respectivas observações, garantindo, assim, o direito da inviolabilidade, à "intimidade, a vida privada, a honra e a imagem das pessoas, assegurado o direito a indenização pelo dano material ou moral decorrente de sua violação", como reza a Constituição Federal de 1988, em seu artigo $5^{\circ}$, inciso X.

Outrossim, a pesquisa embasou-se nas recomendações contidas na Resolução 466, de 12 de dezembro de 2012, propostas pelo Ministério da Saúde que aprova diretrizes e normas regulamentadoras de pesquisas envolvendo seres humanos.

\section{RESULTADOS E DISCUSSÃO}

Atualmente os programas de Educação a Distância vêm aumentando consideravelmente no mundo e, em especial, no Brasil onde 1 milhão de alunos estão matriculados em cursos autorizados pelo MEC, sem falar em 1 milhão e meio em cursos livres, todos na modalidade EAD.

Esse fato ganha força mediante o objetivo precípuo de democratizar a educação no país, inclusive a Educação Superior, como forma de equalizar e garantir um dos princípios da educação brasileira contido na LDB 9.394/96, ou seja, o acesso à educação e permanência com êxito na escola.

Especialistas na área de EAD citam com frequência ranços e avanços na perspectiva do ensinoaprendizagem, tanto no ensino a distância quanto no ensino presencial. Ambos dispõem de desafios, e o maior a ser superado é a questão da disciplina, uma vez que a qualidade do desempenho é responsabilidade quase que exclusiva do aluno, devendo planejar seus horários e fazer pesquisas sobre os conteúdos que não entenderam para retificar dúvidas e complementar a aprendizagem.
Pode-se ter como exemplo de superação de mitos sobre a EAD, a implantação e execução do curso de Medicina EAD - para o qual a LDB estabeleceu dispositivos que tratam da Educação Superior EAD, bem como o Decreto 5.622/2005 e demais portarias ministeriais que regulam tal prática - que, a priori, seria impensável, no entanto, dispondo do vídeo cirurgia e outros instrumentais, os alunos podem praticar como se estivessem tocando no corpo humano por meio de ferramentas tecnológicas.

Nos Ambientes Virtuais de Aprendizagens - AVA, a interação ocorre entre alunos e entre estes com tutores e professores formadores, podendo socializar suas dúvidas, críticas e reflexões através dos fóruns, chats, portfólios, e-mails, videoconferências, audioconferência, teleconferência, blogs, vídeos, fotos etc.

Pode-se perceber quão rica é esta dinâmica de ensino, além de disponibilizar ensino de qualidade em tempo e espaços diversificados, atendendo às peculiaridades de cada educando de maneira salutar ao processo de ensino-aprendizagem. Mesmo havendo desafios, estes são inerentes aos processos que envolvem o ser humano, cabendo assim uma perspectiva do relativismo filosófico e da dialética do conhecimento onde tudo é relativo, incerto e inacabado, oportunizando novas descobertas e avanços.

\subsection{Desafios da Internet para o professor}

A incessante busca de informações por meio da Internet, com todas as suas facilidades, chama a atenção das pessoas, pois apresenta tecnologias funcionais que, a pouco tempo eram difíceis de imaginar.

A chegada da Internet veio revolucionar o processo ensino-aprendizagem, disponibilizando um leque de respostas objetivas para qualquer tema ou assunto. A Internet pode ajudar o professor a preparar melhor a sua aula, intentando a riqueza de diversos matérias disponíveis em rede, e gratuitos com raras exceções. A priori, essa disponibilidade de material pode até assustar o professor, ou deixá-lo inseguro, uma vez que os próprios alunos também têm acesso ao mesmo material de forma democrática e em tempos e locais diferenciados, exigindo assim uma atitude de humildade e redimensionamento da postura do educador, que não é mais detentor exclusivo das fontes de conhecimentos como acreditavam outrora, de acordo com o tradicionalismo exacerbado.

Nesse nexo, o educador deve utilizar o material disponível na internet como forma de consulta, adequando-o à realidade de cada educando, de forma que os tópicos façam sentido em sua vida, configurados através de didática e metodologias coerentes com a prá- 
tica da avaliação que deve ser democrática, mediadora, integradora, predominando os aspectos qualitativos sobre os quantitativos em detrimento da forma de avaliação que serve de violência simbólica, exclusão, punição e classificação.

Ao professor se faz mister, nesse contexto da internet, a criatividade de forma que elabore atividades de pesquisa em grupo, estudos dirigidos e outros processos que, ao final, sejam socializados entre os educandos de modo que haja interação e compreensão dos fundamentos, como peças de uma quebra-cabeça onde cada conhecimento faz parte de um todo, numa visão dialética, respeitando, assim, a pluralidade de conhecimentos e suas maneiras peculiares de fazê-los e descobri-los.

O papel do professor não é o de somente coletar a informação, mas fazer um diagnóstico sobre a relevância da informação ou conteúdo para a vida dos educandos. De que maneira os mesmos irão receber o material e como irão colocar em prática em suas vidas? É um questionamento que remete ao planejamento do plano de aula quando se elenca o objetivo geral e os específicos do tema para assim pensar quais assuntos, habilidades e atitudes que o aluno terá que se apropriar, utilizando aí a consciência criativa, refletiva e crítica que são pressupostos de uma corrente pedagógica progressista "crítico-social dos conteúdos".

O professor não é o "informador", mas o coordenador do processo de ensino-aprendizagem, uma vez que a informação encontra-se difundida em todas as redes e mídias, mas para que ela seja transformada em conhecimento tem que ser reelaborada, utilizando mecanismo de lógica, coerência e concisão, numa perspectiva didática e metodológica de modo a disponibilizar os conteúdos indispensáveis ao convívio, ao respeito às diversidades e ao próprio cosmo, de acordo com os princípios e diretrizes da socioambientalidade.

Morán (1998) reitera interpretando essas premissas, ao afirmar que a Internet é uma formidável ferramenta acessível para profissionais da educação, inclusive educadores de base, pois ela proporciona diversas inovações quanto a abordagem de assuntos, contando com artigos em diversos formatos, filmes, mensagens motivacionais etc., mas ao mesmo tempo assusta os professores excessivamente tradicionais porque estes não conseguem inovar para socializar o conhecimento, querendo atuar ainda como detentores do conhecimento por não aceitarem que com a internet esse monopólio deixou de existir.

\subsection{Conteúdos na plataforma}

Tendo em vista o leque de possibilidades através da internet, os alunos do curso de capacitação foram inda- gados acerca dos conteúdos disponibilizados na plataforma: se eram suficientes, estratégicos e/ou críticoreflexivos, se proporcionava autonomia aos alunos, se haviam desafios e se levava em conta a transdisciplinaridade. Foi constatado, na opinião da maioria dos alunos (80\%), que os conteúdos não foram suficientemente aprofundados, uma vez que não permitia autonomia aos alunos, além de não haver conexão lógica entre os conteúdos. Os participantes da pesquisa responderam ainda acerca da necessidade de um currículo que contemplasse a formação profissional e conteúdos transdisciplinares relacionados ao respeito, à motivação, aos direitos humanos, à formação humana, social, política e planetária.

\subsection{Metodologia}

Quanto a metodologia utilizada na plataforma vale parafrasear Piletti (1995), uma vez que não é novidade que metodologia estuda os métodos de ensino, classificando-os e descrevendo-os sem fazer juízo de valor.

Segundo informações obtidas dos inqueridos, $60 \%$ afirmam que a metodologia utilizada não foi muito dinâmica, visto que os materiais disponibilizados nos slides da plataforma eram insuficientes, sendo proposto que os conteúdos existentes na biblioteca em formato pdf e doc pudessem ser transpostos didaticamente para compor o acervo geral de modo que todos tivessem acesso de forma mais completa e assimilável. Uma minoria $(40 \%)$ respondeu que a metodologia foi coerente aos objetivos da capacitação.

\subsection{Didática}

Posteriormente foi analisado o quesito da Didática aplicada no curso. Parafraseando Piletti (1995), didática é o ramo da Pedagogia que estuda a relação entre teoria e prática no processo de ensino-aprendizagem, fazendo assim um juízo de valor, isto é, um julgamento ou uma crítica do valor dos métodos de ensino. $90 \%$ dos participantes pontuaram positivamente sobre a mesma, no entanto, propuseram que houvesse maior associação entre teoria e prática através de implementação de atividades, exercícios e outras práticas fundadas nas tecnologias digitais.

\subsection{Avaliação}

A avaliação se faz presente constantemente no nosso cotidiano, e na aprendizagem não é diferente, uma vez que devemos utilizar esse processo constantemente em nossas aulas, tendo em vista a mesma não ser fim, mas 

NO IFCE: UMA ANÁLISE DA PRÁXIS PEDAGÓGICA

processo que assegura feedback e constantes mudanças para o aprimoramento das aulas.

Segundo Luckesi (1995), a avaliação da aprendizagem escolar assume funções peremptórias, a saber: diagnóstica - aquela indicada no início do ano letivo, módulo, ou seja, é uma avaliação que visa descobrir os conhecimentos prévios trazidos pelos alunos sobre o assunto que se irá estudar, para que o educador possa através desse diagnóstico saber em que nível eles estão para a escolha de conteúdos adequados àquele nível; formativa - avaliação que ocorre durante aulas, onde as dúvidas são socializadas e sanadas e avaliação somativa a qual diz respeito à transformação dos aspectos qualitativos em quantitativos para classificar de acordo com os critérios legais.

Nesse contexto é pertinente a análise da dicotomia avaliação-exame, uma vez que examinar reporta-se a aplicar questionários, provas e testes para efetuar verificações, enquanto que avaliar é intrínseco ao processo pedagógico, levando em conta não apenas a aplicação de provas e questionários, mas também aspectos que digam respeito à qualidade como atitudes, procedimentos e habilidades ético-morais, sustentabilidade, respeito, tolerância, assiduidade, produtividade, capacidade de iniciativa, criatividade, e outros comportamentos condizentes com os princípios norteadores da condição humana.

Nesse quesito foi citado um leque de ocorrências quais sejam: avaliações dos fóruns - os participantes que responderam o questionário foram unânimes quanto às aprovações das atividades com suas respectivas notas; das tarefas - houve algumas reclamações, por exemplo, uma tarefa não deixava claro o que realmente queria avaliar, sendo necessário enviar diversos e-mails para a tutora. Outro aspecto negativo foi o resultado final do curso que demorou meses para que a lista fosse divulgada, descumprindo diversos prazos estipulados.

\subsection{Logística, plataforma e acesso}

Sobre o acesso ao sistema nenhum participante apontou aspecto negativo, visto que sempre conseguiram se conectar; que a plataforma é de fácil visualização e entendimento, no entanto, as reclamações mais frequentes foram acerca da indisponibilidade de alguns links que foram retificados só depois de muitas queixas por parte dos discentes.

\section{CONSIDERAÇÕES FINAIS}

A Educação a Distância tem a função primordial de democratizar o acesso ao ensino em seus diversos níveis e etapas, uma vez que através de tecnologias e de comuni- cação rápida por meio da internet ocorre a transposição do conhecimento em qualquer tempo e lugar, o que outrora somente acontecia em sala fechada com contato direto entre aluno-professor.

Fator positivo que alguns alunos citaram acerca da EAD refere-se a sua capacidade de construção de conhecimentos de um grande número de pessoas ao mesmo tempo, sendo que essa modalidade exige muito mais do aluno que deve estar motivado e disposto a aprender, portanto terá que planejar-se de acordo com os horários mais viáveis.

Consta-se que no mundo inteiro a EAD cresce de forma frenética, no entanto ainda existem diversos preconceitos e discriminação acerca dessa modalidade, um exemplo categórico, é o curso de Bacharelado em Serviço Social que conta com diversas organizações para impedir a propagação de cursos a distância, inclusive o CFESS (Conselho Federal de Serviço Social) e os CRESS?s (Conselhos Regionais de Serviço Social) têm livros publicados sobre o assunto, afirmando que a modalidade não consegue dar de conta da formação teórico-metodológica, ético-política e técnicooperacional dos profissionais e que sua consequente massificação redunda na oferta de baixos salários por parte dos empregadores. Uma estratégia proposta pelo CFESS, CRESS e outras entidades seria a difusão de cursos de Serviço Social na rede pública, em especial no Ceará, que conta apenas com dois bacharelados em universidades públicas, UECE e IFCE Iguatu. O IFCE está com chamada e consulta pública abertas para abrir mais um curso público e gratuito no campus Canindé.

Esse exemplo serve para que se possa fazer uma reflexão acerca dos mitos e verdades ideológicas. Acredita-se que deva haver uma mobilização da classe e conselhos em prol de uma mudança por parte do MEC, onde se invista na formação de qualidade, com recursos suficientes, ao invés de atacar os formados e formandos por essa modalidade de ensino que, na maioria das vezes, é a única disponível devido aos horários do aluno trabalhador.

Acerca dos conteúdos ministrados ainda há muito o que melhorar, como foi colocado em relação ao aprofundamento dos temas que ficaram muitos espessos; quanto à metodologia foi considerada acessível e refletiu os objetivos do curso, no entanto, teria que ser mais dinâmica. Sobre a didática percebeu-se que foi positiva. Em relação à avaliação constatou-se que as maiores reclamações estão ligadas à questão de notas e divulgação das mesmas em tempo hábil. No que tange à logística, plataforma e ao acesso, a maioria (\%) colocou como positivos, ressaltando, apenas, a inacessibilidade de alguns links. 
CAPACITAÇÃO EM EAD PARA TUTORES NO CURSO DE ESPECIALIZAÇÃO EM FORMAÇÃO PEDAGÓGICA PARA DOCENTES NO IFCE: UMA ANÁLISE DA PRÁXIS PEDAGÓGICA

Mesmo sendo antiga, para a Educação a Distância no Brasil ainda falta investimento do poder público para sua concretização, de forma a democratizar o ensino público onde todos possam ter acesso, atendendo as peculiaridades, inclusive regionais e climáticas, dos locais em que a educação presencial se torne inviável à realidade do cursista.

\section{REFERÊNCIAS}

ALVES, A. J. O planejamento de pesquisas qualitativas em educação. Cadernos de pesquisa, v. 1, n. 77, p. 53-61, maio 1991.

BOGDAN, R. C. et al. Investigação qualitativa em educação: uma introdução à teoria e aos métodos. Porto, Portugal: Porto Editora, 1994.

BRASIL. Lei $n^{o} .9394$ de 20 de dezembro de 1996. Estabelece as Diretrizes e Bases da Educação Nacional. 1996. Disponível em: <http: //www.planalto.gov.br/ccivil_03/Leis/L9394.htm> Acesso em: 13 jan. 2016.

- Constituição da República Federativa do Brasil de 1988. 1998. Disponível em: <http://portal.mec.gov.br/arquivos/pdf/ldb.pdf> Acesso em: 13 jan. 2016.

Decreto $n^{\circ} 2494$, de 10 de fevereiro de 1998. Regulamenta o Art. 80 da LDB (Lei n. ${ }^{\circ}$ 9.394/96). 1998. Disponível em: <http://portal.mec.gov.br/seed/ arquivos/pdf/tvescola/leis/D2494.pdf>, Acesso em: 13 jan. 2016.

. Decreto $n^{\circ}$ 5.622, de 19 de dezembro de 2005. Regulamenta o art. 80 da lei no 9.394, de 20 de dezembro de 1996, que estabelece as diretrizes e bases da educação nacional. 2005. Disponível em: <http: //portal.mec.gov.br/seed/arquivos/pdf/dec_5622.pdf> Acesso em: 13 jan. 2016.

. Decreto $n^{\circ}$ 5.773, de 09 de maio de 2006. Dispõe sobre o exercício das funções de regulação, supervisão e avaliação de instituições de educação superior e cursos superiores de graduação e sequenciais no sistema federal de ensino. 2006. Disponível em: <http://portal.mec.gov.br/seed/arquivos/pdf/legislacao/ decreton57731.pdf $>$ Acesso em: 13 jan. 2016.

. Decreto $n^{\circ}$ 6.303, de 12 de dezembro de 2007. Altera dispositivos dos Decretos nos 5.622, de 19 de dezembro de 2005, que estabelece as diretrizes e bases da educação nacional, e 5.773, de 9 de maio de 2006, que dispõe sobre o exercício das funções de regulação, supervisão e avaliação de instituições de educação superior e cursos superiores de graduação e sequenciais no sistema federal de ensino. 2007. Disponível em: <http://www.planalto.gov.br/ccivil_03/ _Ato2007-2010/2007/decreto/D6303.htm> Acesso em: 13 jan. 2016.

Portaria $n^{\circ}$ 10, de 02 de julho de 2009. Fixa critérios para dispensa de avaliação in loco e dá outras providências. 2009. Disponível em: <http:// portal.mec.gov.br/dmdocuments/portaria10_seed.pdf $>$. Acesso em: 13 jan. 2016.

Conselho Nacional de Saúde. Resolução $\overline{466}$, de 12 de dezembro de 2012. Aprova diretrizes e normas regulamentadoras de pesquisas envolvendo seres humanos. 2012. Disponível em: <http://bvsms.saude.gov.br/bvs/saudelegis/cns/2013/ res0466_12_12_2012.html>. Acesso em: 13 jan. 2016.

Instituto Federal de Educação, Ci-

ência e Tecnologia do Ceará. 2016.

Disponível em: <http://www.ifce.edu.br/ 2757-educacao-a-distancia-apresentacao\#uab> Acesso em: 13 jan. 2016.

GIL, A. C. Como elaborar projetos de pesquisa. 4. ed. São Paulo: Atlas, 2008.

GOUVÊA, G.; OLIVEIRA, C. I. Educação a distância na formação de professores: viabilidades, potencialidades e limites. 4. ed. Rio de Janeiro: Vieira \& Lent, 2006.

LUCKESI, C. C. Avaliação da aprendizagem escolar: estudos e proposições. 6. ed. São Paulo: Cortez editora, 1995.

Filosofia da Educação. 19. ed. São Paulo: Cortez, 2003.

MAIA, C.; MATTAR, J. ABC da EaD. 1. ed. São Paulo: Pearson Prentice Hall, 2007.

MARCONCIN, M. A. Desenvolvimento histórico da Educação a Distância no Brasil. 2010. Disponível em: <http://www.followscience.com/account/blog/article/ 106/desenvolvimento-historico-da-educacao-a-> Acesso em: 13 jan. 2016.

MERCADO, L. P. L. A Internet como ambiente auxiliar do professor no processo ensino aprendizagem. 2017. Disponível em: <http://www.educoas.org/virtualeduca/ virtual/actas2002/actas02/211.pdf $>$ Acesso em: 31 jan. 2017. 
MINAYO, M. C. d. S. A análise de dados em pesquisa qualitativa. 17. ed. Petrópolis, R: Vozes Petrópolis, 1994. 67-80 p.

MORÁN, J. M. Internet no ensino. Comunicação \& Educação, v. 14, n. 1, p. 17-26, 1998.

. O que é Educação a Distância. São Paulo, 2016.

PILETTI, C. Didática Geral. 18. ed. São Paulo: Ática, 1995.

RODRIGUES, M. Universidade Aberta do Brasil. 2010. Disponível em: <http://www. vestibular.brasilescola.com/ensino-distancia/ universidade-aberta-brasil.htm>. Acesso em: 13 jan. 2016.

RUIZ, J. A. Metodologia científica: guia para eficiéncia nos estudos. 5. ed. São Paulo: Atlas, 2002.

SANTOS, P. SEED - Secretaria de Educação a Distância. 2010. Disponível em: <http://portal.mec.gov. br/index.php?option=com_docman\&view=download\& alias=16181-relatorio-gestao-seed-2008-pdf\&Itemid= 30192> Acesso em: 13 jan. 2016.

VASCONCELOS, S. P. G. Educação a Distância: histórico e perspectivas. 2010. Universidade do Estado do Rio de Janeiro (UERJ). Disponível em: <http://www.ifce.edu.br/ 2757-educacao-a-distancia-apresentacao\#editais> Acesso em: 13 jan. 2016.

\section{APÊNDICE}

1. Os conteúdos disponibilizados na plataforma foram suficientes e coerentes com os objetivos almejados?

2. A plataforma foi de fácil acesso possibilitando a visualização rápida e dinâmica?

3. As notas foram postadas em tempo hábil?

4. A metodologia se mostrou adequada?

5. O processo de comunicação e interação com a tutora se mostrou eficiente e eficaz?

6. Os conteúdos expostos na plataforma foram selecionados e elaborados de forma didática ou apenas conteúdista-verbalista?

7. As tarefas, atividades e fóruns propostos condiziam com os conteúdos trabalhados?

8. Em que aspecto os conteúdos do curso deveriam ou poderiam melhorar?

Conex. Ci. e Tecnol. Fortaleza/CE, v. 11, n. 2, p. 36 - 44, jul. 2017
9. Na avaliação dos alunos se pôde perceber a prevalência dos aspectos qualitativos sobre os quantitativos?

10. Sobre o curso, didática, metodologia, conteúdos e avaliação. Na sua opinião o que poderia melhorar? 